\title{
Deposition Time induced Structural and Optical Properties of Lead Tin Sulphide Thin Films
}

\author{
J. Damisa ${ }^{\mathrm{a}, *}$, J.O. Emegha ${ }^{\mathrm{a}}$, I.L. Ikhioya ${ }^{\mathrm{b}}$ \\ ${ }^{a}$ Department of Physics, University of Benin, Benin City, Edo State, Nigeria \\ ${ }^{b}$ Department of Physics and Astronomy, University of Nigeria, Nsukka, Enugu State, Nigeria
}

\begin{abstract}
Lead tin sulphide (Pb-Sn-S) thin films (TFs) were deposited on fluorine-doped tin oxide (FTO) substrates via the electrochemical deposition process using lead (II) nitrate $\left[\mathrm{Pb}\left(\mathrm{NO}_{3}\right)_{2}\right]$, tin (II) chloride dehydrate $\left[\mathrm{SnCl}_{2} .2 \mathrm{H}_{2} \mathrm{O}\right]$ and thiacetamide $\left[\mathrm{C}_{2} \mathrm{H}_{5} \mathrm{NS}\right]$ precursors as sources of lead $(\mathrm{Pb})$, tin $(\mathrm{Sn})$ and sulphur $(\mathrm{S})$. The solution of all the compounds was harmonized with a stirrer (magnetic) at $300 \mathrm{k}$. In this study, we reported on the improvements in the properties (structural and optical) of Pb-Sn-S TFs by varying the deposition time. We observed from X-ray diffractometer (XRD) that the prepared material is polycrystalline in nature. UV-Vis measurements were done for the optical characterizations and the band gap values were seen to be increasing from 1.52 to $1.54 \mathrm{eV}$ with deposition time. In addition to this, the absorption coefficient and refractive index were also estimated and discussed.
\end{abstract}

DOI:10.46481/jnsps.2021.157

Keywords: Thin films, XRD, band gap, $\mathrm{Pb}-\mathrm{Sn}-\mathrm{S}$, refractive index, absorption coefficient

Article History :

Received: 19 January 2021

Received in revised form: 17 September 2021

Accepted for publication: 18 September 2021

Published: 29 November 2021

(c)2021 Journal of the Nigerian Society of Physical Sciences. All rights reserved. Communicated by: B. J. Falaye

\section{Introduction}

Tin sulphide $(\mathrm{SnS})$ is a potential material for the production of thin solar cells because of its high absorption coefficient ( $\alpha \approx 10^{4} \mathrm{~cm}^{-1}$ near the fundamental edge), suitable band gap ( $\left.\mathrm{E}_{g}=1.1-2.1 \mathrm{eV}\right)$ and high hole mobility of $90 \mathrm{~cm}^{3} V^{-1} S^{-1}$ [1-3]. SnS semiconductors could present $\mathrm{p}$ or n-type conductivity owing to the preparation conditions and doping materials, which allow the films to be used as an absorption layers in hetero-junction solar cells fabrication $[1,4,5]$. Theoretically, $\mathrm{SnS}$ thin films solar cells can be optimized such that a conversion efficiency of above $25 \%$ can be reached [6]. SnS thin films

\footnotetext{
${ }^{*}$ Corresponding author tel. no: +234 (0) 7060515540

Email address: john.damisa@uniben.edu (I.L. Ikhioya)
}

has been prepared by several methods like thermal evaporation, spray pyrolysis, electron beam evaporation, SILAR, hot injection, aqueous solution, colloidal route, single solid approach, precipitation and electrochemical deposition (ECD) [5-7]. ECD technique was used to fabricate $\mathrm{Pb}-\mathrm{Sn}-\mathrm{S}$ thin films in this study. The method presents a simple route of depositing TFs due to its low cost of experimental system, uniformity of films thickness as well as its large area deposition at low temperature [8-10].

Recently, investigation into new photovoltaic materials with improved efficiency have assumed a considerable interest and researchers are investigating for understanding and engineering the properties of SnS TFs for photovoltaic application [5]. Doping with elements like lead has shown to enhance the structural as well as the optical properties of SnS TFs. The study presents the preparation of lead tin sulphide $(\mathrm{Pb}-\mathrm{Sn}-\mathrm{S})$ thin films using 


\section{Results and Discussion}

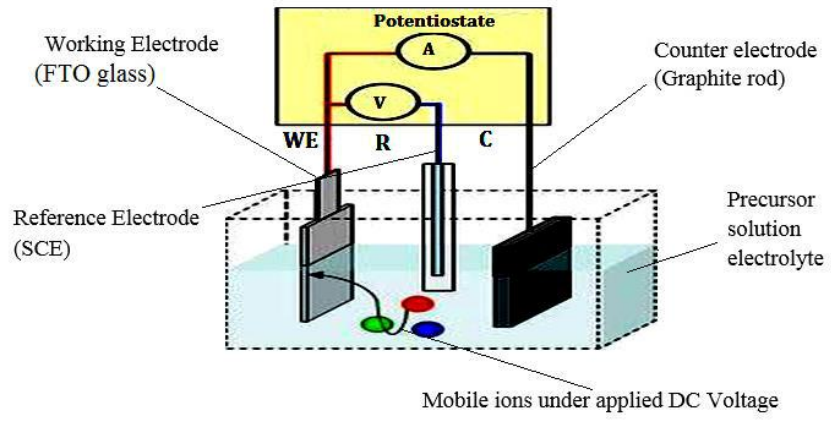

Figure 1. Schematic diagram of $\mathrm{Pb}-\mathrm{Sn}-\mathrm{S}$ deposition process

the electrochemical deposition technique. Our aim is to develop a better growth approach of new and non-toxic material for the production of low cost solar cells. Improvement in the properties of SnS TFs due to lead incorporation in SnS-system will enhance the device efficiency of the material. Particularly, this communication is concerned with the influenced of deposition duration on the properties (structural and optical) of $\mathrm{Pb}-\mathrm{Sn}-\mathrm{S}$ TFs via the electrochemical deposition technique which hitherto has not been studied using this route.

\section{Materials and Method}

Analytically graded chemical (Sigma-Aldrich) was used to deposit the Pb-Sn-S TFs. These chemicals include; lead (II) nitrate $\left[\mathrm{Pb}\left(\mathrm{NO}_{3}\right)_{2}\right]$, tin (II) chloride dehydrate $\left[\mathrm{SnCl}_{2} \cdot 2 \mathrm{H}_{2} \mathrm{O}\right]$ and thiacetamide $\left[\mathrm{C}_{2} \mathrm{H}_{5} \mathrm{NS}\right]$. The electrochemical deposition bath system consist of a cationic precursor of $0.05 \mathrm{~mol}$ of $\mathrm{Pb}\left(\mathrm{NO}_{3}\right)_{2}$, $0.01 \mathrm{~mol}$ of $\mathrm{SnCl}_{2} .2 \mathrm{H}_{2} \mathrm{O}$ and an anionic (precursor) of $0.15 \mathrm{~mol}$ of $\mathrm{C}_{2} \mathrm{H}_{5} \mathrm{NS}$ mixed in distilled water. A stirrer (magnetic) was used to harmonize the reaction bath. Fluorine doped Tin Oxide (FTO) and carbons were employed as the cathode and anode electrodes respectively. The deposition using the electrochemical deposition method was achieved according to the scheme in Figure 1. The deposition were repeated for 20, 25, 30, 35 and 40 seconds and the samples were later coded as J0, J1, J2, J3, and $\mathrm{J} 4$ respectively.

\subsection{Characterization of thin films}

The Pb-Sn-S films used for this study have good adherent with the FTO substrates. The XRD patterns of $\mathrm{Pb}-\mathrm{Sn}-\mathrm{S}$ TFs were observed using Advanced X-ray diffractometer (Bruker D8) operating with a wavelength of $1.5406 \dot{A}$ and, at a scanning range of 15 to $80^{\circ}$. The UV-Visible optical measurements of $\mathrm{Pb}-\mathrm{Sn}-\mathrm{S}$ thin films were done using a UV-1800 Spectrophotometer in the range of 300 to $1000 \mathrm{~nm}$ at room temperature. The optical band gaps (Eg), absorption coefficient $(\alpha)$ as well as refractive index (n) were estimated from the optical data.

\subsection{X-ray diffraction $(X R D)$ studies}

The XRD patterns of $\mathrm{Pb}-\mathrm{Sn}-\mathrm{S}$ TFs are shown in Figure 2. Although the deposition time is increased, the XRD spectra showed four similar main peaks at $21.70 \circ, 23.50^{\circ}, 24.94^{\circ}$ and $33.62^{\circ}$, which correspond to the diffraction peaks of (200), (201), (211) and (221). The presence of higher intensity peaks in the Pb-Sn-S films with narrower spectral widths indicated that the films are polycrystalline in nature [11, 12]. From the $\mathrm{XRD}$ patterns also, it is obvious that the $\mathrm{Pb}-\mathrm{Sn}-\mathrm{S}$ structures consist of mixtures of several phases including the orthorhombic Sn2S3 (JCPDS no 014-0619), hexagonal SnS2 (JCPDS no 0230677) and cubic structure PbS thin films (JCPDS 01-0880). As known, the presence of secondary phases within the $\mathrm{Pb}-\mathrm{Sn}-\mathrm{S}$ system may have deteriorated the structural crystallization as well as the peaks patterns.

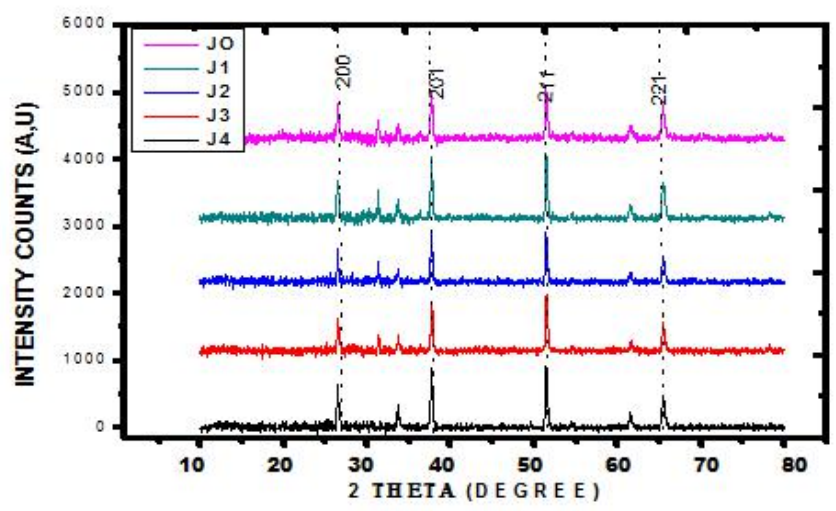

Figure 2. XRD patterns of the prepared PbSnS thin film

\subsection{Optical studies}

To ascertain the potentials of the electrochemical prepared $\mathrm{Pb}-\mathrm{Sn}-\mathrm{S} \mathrm{TFs}$ for device fabrications, the absorbance was investigated in the spectra wavelength of 300 to $1000 \mathrm{~nm}$. The absorbance $\mathrm{A}$, was measured using the relation in equation(1) [13];

$$
A=\log \left(\frac{1}{\mathrm{~T}}\right)
$$

Figure 3 shows the relationship between the optical absorbance and wavelength of Pb-Sn-S FTs. In the plot, it could be observed that the absorption was decreasing along the wavelength regions. As well from the figure, the absorbance decreases with deposition time. Such decrease in absorbance may be due to structural defects such as surface irregularity and defect density in the $\mathrm{Pb}-\mathrm{Sn}-\mathrm{S}$ system as a result of increase in deposition time [14], as indicated from the XRD measurement. The low absorbing nature of the films consequently indicates an improvement in the transmission [13]. The absorption coefficient $(\alpha)$ of the material was evaluated by means of the equation (2) [15];

$$
\alpha=\frac{1}{t} \ln \left(\frac{1}{\mathrm{~T}}\right)
$$


Table 1. Some optical properties of Pb-Sn-S TFs

\begin{tabular}{cccc}
\hline Samples & Band gap & Absorption coefficient & Refractive index \\
\hline & $(\mathrm{eV})$ & $\left(\mathrm{cm}^{-1}\right) \times 10^{4}$ & $(\mathrm{n})$ \\
\hline JO & 1.51 & 6.10 & 2.944 \\
J1 & 1.52 & 15.0 & 2.939 \\
J2 & 1.53 & 17.5 & 2.934 \\
J3 & 1.54 & 13.2 & 2.929 \\
J4 & 1.51 & 6.80 & 2.944 \\
\hline
\end{tabular}

Equation (2) assumed a negligible reflectance while $\mathrm{T}$ and $\mathrm{t}$ are the respective transmittance and thickness of $\mathrm{Pb}-\mathrm{Sn}-\mathrm{S}$ films. The observed variation of the absorption coefficient with deposition time is shown in Table 1. It was observed that $\alpha$ increased from $6.1 \times 10^{4}$ to $17.5 \times 10^{4} \mathrm{~cm}^{-1}$ with deposition time of 30 seconds (Sample J2) and was decreased on further increase of deposition time. Also from the table, the magnitude of the absorption coefficient was found to be greater than the $10^{4} \mathrm{~cm}^{-1}$ which makes $\mathrm{Pb}-\mathrm{Sn}-\mathrm{S}$ thin film a better alternative than $\mathrm{GaAs}$ and CdTe as absorber layers in photovoltaic applications $[5,16]$. The band gap (direct) was determined using the following rela-

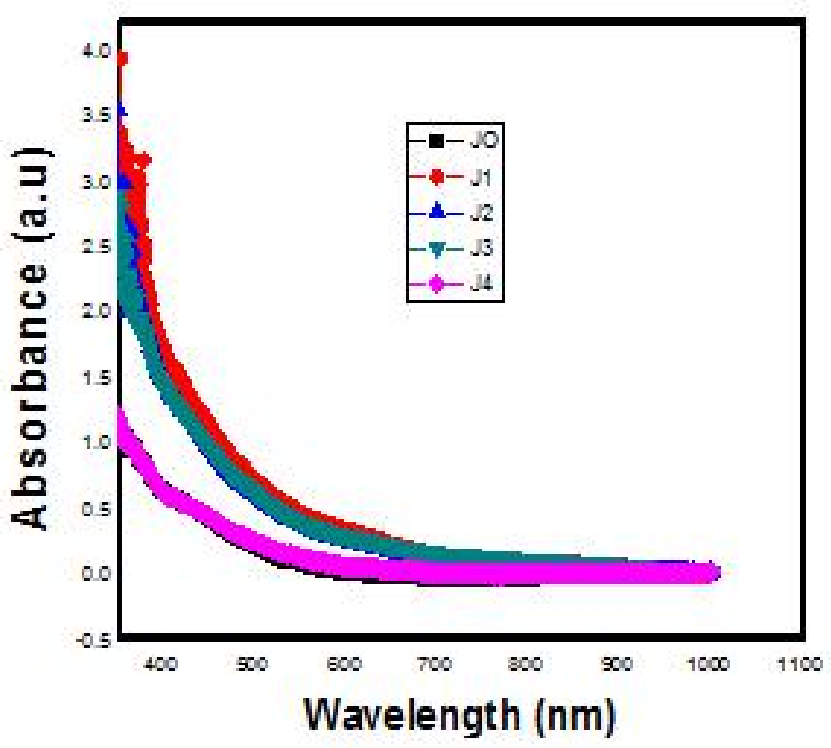

Figure 3. Absorbance against wavelength of the prepared PbSnS thin films

tion in equation(3) [17];

$$
(\alpha h v)^{2}=k(h v-E g)
$$

where $h v$ is the photon energy, $\alpha$ is the absorption coefficient, $\mathrm{k}$ is a proportionality constant, and Eg is the optical band gap. A plot of the square of absorption coefficient against photon energy gives a curve illustrated in Figure 4. Since the prepared $\mathrm{Pb}-\mathrm{Sn}-\mathrm{S}$ films is a direct semiconducting material [2], extrapolating the linear portion of Figure 4 to the $\mathrm{x}$-axis at $\mathrm{x}=0$ gives the band gap energy (Eg). The band gap obtained was seen to be between $1.52-1.54 \mathrm{eV}$ as indicated in Table 1. Also from the table, the band gap energy values were observed to be increasing with increase in deposition time. Generally, band gap energy in semiconducting materials are mostly influenced by their structural defects, crystallinity, impurities, grain sizes as well as grain boundary disorders [18].

Consequently, the observed increase in band gap energy in $\mathrm{Pb}-\mathrm{Sn}-\mathrm{S}$ samples can be explained in terms of the effect of impurities in their lattice system as indicated from the XRD studies. Sebastian et al. [2] have reported a band gap range of 1.60 to $1.90 \mathrm{eV}$ for lead doped tin sulphide $(\mathrm{SnS}: \mathrm{Pb}) \mathrm{TFs}$ grown by varying lead concentration using Nebulized spray pyrolysis (NSP) technique. Orimi et al. [19] estimated an optical band gap of 1.63 to $1.80 \mathrm{eV}$ for Pb1-xSnxS nano-powder using chemical precipitate technique. Our obtained values are relatively lower than these values which could be the direct effect of the electrochemical deposition method employed in the preparation of this film.

The refractive index (n) is an essential property of optical materials. It is closely related to the electronic polarization of ions as well as the local field within the optical materials [20]. Many optoelectronic devices such as switches, modulators, filters, waveguides, solar cells and detectors are based on refractive index [21]. Generally, the $\mathrm{n}$ of $\mathrm{Pb}-\mathrm{Sn}-\mathrm{S}$ TFs is related to the optical band gaps. Moreover, the refractive index of the prepared $\mathrm{Pb}-\mathrm{Sn}-\mathrm{S}$ films was estimated using the proposed relation by Herve and Vandamme, given in equation (3) [21, 22]

$$
n=\left[1+\left.\left(\frac{A}{E g+B}\right)^{2}\right|^{\frac{1}{2}}\right.
$$

where $\mathrm{Eg}$ is the band gap, A $(13.6 \mathrm{eV})$, and $\mathrm{B}(3.4 \mathrm{eV})$ are constants. The estimated values of the refractive index are indicated in Table 1. The results indicated that the $n$ values of $\mathrm{Pb}-\mathrm{Sn}-\mathrm{S}$ TFs decreased from 2.944 to 2.929 with enhance deposition time. The range of the refractive indices of the material indicate that $\mathrm{Pb}-\mathrm{Sn}-\mathrm{S}$ film is a ternary material whose properties falls between the binary constituents of $\mathrm{PbS}(1.8-6.0)$ [23] and SnS (3.5 - 5.5) [4], and compares favorable well with values in literature.

\section{Conclusion}

Thin films of $\mathrm{Pb}-\mathrm{Sn}-\mathrm{S}$ have been prepared by the electrochemical deposition method and the structural and optical properties were investigated as function of the deposition time. The XRD measurements indicated a polycrystalline film with no much difference in their crystallinity as deposition time increases. The increased deposition time resulted in the variation of the 


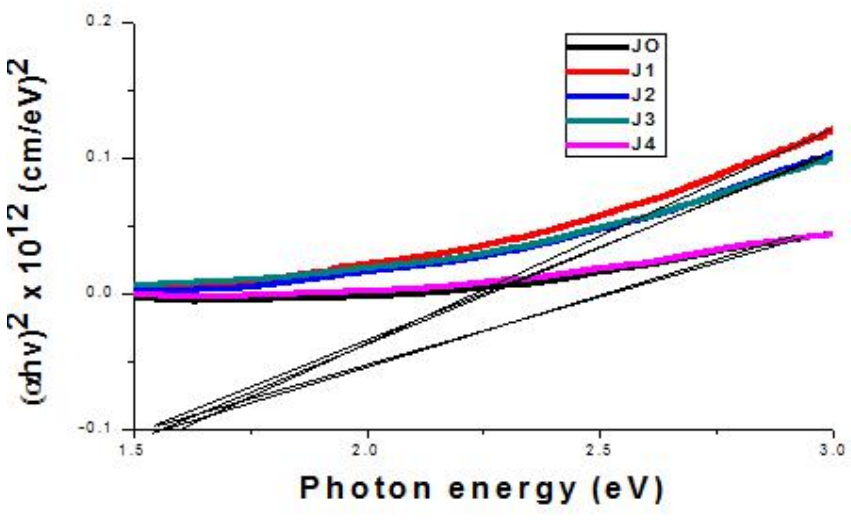

Figure 4. Square of absorption coefficient and photon energy for Pb-Sn-S TFs

absorption coefficient and band gap from $6.1 \times 10^{4}$ to $17.5 \times$ $10^{4} \mathrm{~cm}^{-1}$ and 1.51 to $1.54 \mathrm{eV}$ respectively. The refractive index was observed to decrease with deposition time except for sample $\mathrm{J} 4$, and obeyed the Harve and Vandamme model. The high absorption coefficient obtained for the material suggests that the prepared $\mathrm{Pb}-\mathrm{Sn}-\mathrm{S}$ would create good absorbing properties in solar cell fabrications.

\section{Acknowledgments}

We thank the reviewers as well as the editorial team for their positive contributions and ideas, which have markedly enhanced the value of this paper.

\section{References}

[1] E. Guneri, F. Gode, C. Ulutas, F. Kirmizigul, G. Altindemir. \& C. Gumus, "Properties of P-type SnS thin films prepared by chemical bath deposition", Chalcogenide Letter, 7 (2010) 685-694.

[2] S. Sebastian, I. Kulandaisamy, S. Valanarasu, I. S. Yahia, H. Kim. \& D. Vikraman, "Microstructural and electrical properties evaluation of lead doped tin sulphide thin films", Journal of Sol-Gel Science and Technology $98(2020) 52$.

[3] S.N. Nwankwo, S. Campbell, R.K.T. Reddy, N.S. Beattie, V. Barrioz, \&. G Zoppi, "Temperature controlled properties of submicron thin SnS films", Semiconductor Science and Technology, (2018). DOI:10.1088/1361-6641/aabc6f.

[4] P.A. Nwofe, K.T. Ramakrishna Reddy, J. K. Tan, I. Forbes, \& R.W. Miles, "Thickness dependent optical properties of thermally evaporated $\mathrm{SnS}$ thin films", Physics Procedia 25 (2012) 150.

[5] G.H. Tariq, K. Hutchings, G. Asghar, \& D.W. Lane, "Study of annealing effects on the physical properties of evaporated $\mathrm{SnS}$ thin films for photovoltaic applications", Journal of Ovonic Research, 6 (2014) 247.

[6] C.L.C. Triana, E. Banguero, P. Bartolo-Perez, \& Gordillo, "Preparation and characterization of SnS:Bi thin films", Brazilian Journal of Physics, 41 (2011) 15.
[7] A.E. Oluwalana, \& P.A. Ajibade, "Effect of temperature and capping agents on structural and optical properties of tin sulphide nanocrystals", Journal of Nanotechnology, (2019) DOI: 10.1155/2019/8235816.

[8] I.L. Ikhioya, \& A.J. Ekpunobi, "Effect of deposition period and pH on electrodeposition technique of zinc selenide thin films", Journal of Nigerian Association of Mathematical Physics, 28 (2014) 281.

[9] I.L. Ikhioya, M.C. Ezeorba, D.O. Okoroh, C.R. Anene, \& C.O. Obasi, "The Influence of precursor temperature on the properties of ErbiumDoped Zirconium Telluride thin film material via electrochemical deposition", International Journal of Applied Physics, (SSRG-IJAP), 7 (2020) 102.

[10] I.L. Ikhioya, \& A. J. Ekpunobi, "Electrical and Structural properties of ZnSe thin films by Electrodeposition technique", Journal of Nigerian Association of Mathematical Physics, 29 (2015) 325.

[11] R. Wahab, Y.S. Kim, \& H.S. Shin," Synthesis, characterization and effect of ph variation on zinc oxide nanostructures", Materials Transactions, $\mathbf{5 0}$ (2009) 2092.

[12] J.O. Emegha, B. Olofinjana, M.A. Eleruja, O. Efe, \& S.O. Azi, "Preparation and physical properties of CuxZn1-xS thin films deposited by metal organic chemical vapour deposition technique", Journal of Materials Science Research and Reviews, 2 (2019) 1. DOI: 10.9734/JMSRR/2019/46490.

[13] J.O. Emegha, J. Damisa, F.O. Efe, B. Olofinjana, M.A. Eleruja, \& S.O. Azi, "Preparation and characterization of metal organic chemical vapour deposited copper zinc sulphide thin films using single solid source precursors", European Journal of Materials Science and Engineering, 4 (2019) 11. DOI: 10.36868/ejmse.2019.04.01.011.

[14] J.O. Emegha, M.C. Okafor, \& K.E. Ukhurebor, "Optical properties of copper-zinc sulphide network from mixed single solid source precursors of copper and zinc dithiocarbamates", Walailak Journal of Science and Technology, 18 (2021) 9535. DOI:10.48048/WJST.2021.9535.

[15] J. Damisa, B. Olofinjana, O. Ebomwonyi, F. Bakare, \& S.O. Azi, "Morphological and optical study of thin films of CuAlS2 deposited by metal organic chemical vapour deposition technique", Materials Research Express 4 (2017) 1

[16] M.F. Bin Hashim, Morphologies, Optical and Electrical Characterization of Aluminum Tin Sulphide Thin Films, Master of Philosophy Dissertation, Universiti Teknologi Malaysia, 2017.

[17] M. Arslan, A. Habib, M. Zakria, \& A. Mehmood, "Elemental, structural and optical properties of nanocrystalline $\mathrm{Zn}_{1-x} \mathrm{Cu}_{x} \mathrm{Se}$ films deposited by close spaced sublimation technique", Journal of Science: Advanced Materials and Devices, 2 (2017) 79.

[18] B. Olofinjana, A.C. Adebisi, F.O. Efe, O. Fasakin, K.O. Oyedotun, M.A. Eleruja, E.O.B. Ajayi, \& N. Manyala, "Single solid source precursor route to the synthesis of MOCVD Cu-Cd-S thin films", Materials Research Express, 6 (2019). DOI: 10.10688/2053-1591/ab413a

[19] R.L. Orimi, H.K. Fadafan, \& A. Asadpour "Effect of Sn concentration on the optical and structural properties of $\mathrm{Pb}_{1-x} \mathrm{Sn}_{x} \mathrm{~S}$ nanopowder", The European Physical Journal (Applied Physics) (2014). DOI:10.1015/epjap/2014140159

[20] A.S. Hassanien, \& A.A. Akl, "Influence of composition on optical and dispersion parameters of thermally evaporated non-crystalline $\mathrm{Cd}_{50} \mathrm{~S}_{50-x} \mathrm{Se}_{x}$ thin films, Journal of Alloys and Compounds 648 (2015) 280.

[21] K.S. Ajay, "An empirical relation showing the variation of refractive index with energy gap for $\mathrm{A}^{1} \mathrm{~B}^{111} \mathrm{C} 2^{v 1} \& \mathrm{~A}^{11} \mathrm{~B}^{1 v} \mathrm{C} 2^{v}$ type ternary semiconductors" International Journal of Innovative Research in Technology 5 (2018) 85.

[22] S. Ahmad, M. Ashraf, \& Aijaz Ahmad, "Electronic and optical properties of semiconductor and alkali halides", Arabian Journal for Science and Engineering 38 ( 2013) 1889.

[23] M. M. Abbas, A.A. Shehab, A. Al-Samuraee, \& N.A. Hassan, "Effect of deposition time on the optical characteristics of chemically deposited nanostructure PbS thin films", Energy Procedia 6 (2011) 241. 